\title{
Predictive role of serum rheumatoid factor in different disease pattern of psoriasis and psoriatic arthritis
}

\author{
Enas Zahran' ${ }^{1}$, Ali Youssof ${ }^{2}$, Wafaa Shehata ${ }^{3}$, Ahmed Bahgat ${ }^{4}$ and Emad Elshebiny ${ }^{1^{*}}$ (D)
}

\begin{abstract}
Background: Psoriasis is a multisystem inflammatory disorder with variable morphology, clinical pattern and multiple comorbidities. Interplay between genetic and environmental factors leading to an aberrant immune response in the skin may contribute to disease development. The assessment for risk factors, signs, and symptoms of potential comorbid diseases is an important component of patient management. The aim of this study is to determine rheumatoid factors (RF) positivity and its levels in psoriasis patients, and describe its relationship with the demographic and clinical characteristics, comorbidities, and disease patterns of psoriasis.

Results: Rheumatoid factor was positive in psoriatic patients more than control,30\% of patients had positive rheumatoid factor while only $10 \%$ of control had positive results. Rheumatoid factor level was $63.8 \pm 186.7 \mathrm{IU} / \mathrm{ml}$ in psoriasis vs. $9.3 \pm 12.3$ in control. Thirty percent of psoriasis patients have positive rheumatoid factor vs. $10 \%$ of control. There was no significant statistical difference between psoriasis patients with or without arthritis as regard rheumatoid factor positivity and titer; rheumatoid factor was positive in $20 \%$ in psoriatic patients with arthritis vs. $26 \%$ in psoriatic patients without arthritis. In psoriatic patients, the status of rheumatoid factor did not relate to disease severity, onset, course, site of affection, presence of scalp, nail affection, and presence of dactylitis ( $p$ value $>0.5$ ).
\end{abstract}

Conclusion: Psoriasis was associated with higher seropositivity of RF compared to age-matched non-psoriatic healthy controls. Occurrence and level of rheumatoid factor were not associated with severity or clinical pattern of psoriasis.

Keywords: Case-control study, Rheumatoid factor, Psoriasis, Psoriatic arthritis

\section{Background}

Rheumatoid factors (RFs) are antibodies against the Fc portion of immunoglobulin G (IgG), Although they gain their name because of their first detection in RA patients, RFs are found in patients with other autoimmune and non-immune diseases, as well as-in healthy people. RF is not routinely detected in the absence of an antigenic stimulus; as direct infection by virus, chronic antigenic stimulation by immune complexes $[1,2]$.

\footnotetext{
*Correspondence: emadelshebini@gmail.com

${ }^{1}$ Rheumatology Immunology Division, Internal Medicine Department Faculty of Medicine Menoufia University, Shebin El Kom, Menoufia, Egypt Full list of author information is available at the end of the article
}

RF has some potentially pathogenic and other potentially beneficial activities. There is evidence that RF may promote pathological inflammatory cytokine production through interactions with anti-citrullinated peptide antibodies (ACPA) immune complexes in rheumatoid arthritis. Possible beneficial functions include processing of antigens in immune complexes, Presentation of antigens to $\mathrm{T}$ lymphocytes, Immune tolerance, amplification of the humoral response to infection and Immune complex clearance [3-5].

Psoriasis is a chronic inflammatory papulosquamous cutaneous disease with dysregulated keratinization manifested by well-demarcated, erythematous plaques with silver scales and associated with variable comorbidities. 
Different presentations might occur such as guttate, pustular, erythrodermic, inverse, and nail psoriasis. The international prevalence of psoriasis is approximately $2-3 \%$ with a much lower prevalence in younger ages. The peak age at onset in adults is in the third and fourth decade of life, with a slight more prevalence in males. There is no clear definition or diagnostic criteria proposed for psoriasis and the diagnosis is essentially clinical $[6,7]$.

Dysregulation of the immunity is now recognized as a critical event in this disease; suggested by the inflammatory response in the psoriatic skin and synovial lesions. IL-23 and IL-12 produced by activated dendritic cells promote the development of Th17 and Th1 cells [8].

Psoriatic arthritis (PsA) is a type of inflammatory arthritis that occur in up to $30 \%$ of patients with psoriasis; which may be peripheral, axial, or both. It present as an asymmetric oligoarthritis, symmetrical polyarthritis, arthritis of the distal interphalangeal (DIP) joints, as a destructive arthritis (arthritis mutilans), or as a spondyloarthritis. Patterns often overlap; enthesitis, dactylitis, and tenosynovitis can also occur. Other forms of arthritis can occur in patients with psoriasis, such as rheumatoid arthritis, osteoarthritis, gout, reactive arthritis, and the arthritis of inflammatory bowel disease [9]. The exclusion of other arthropathies is dependent on the pattern of joint involvement, serological markers, joint imaging, and synovial aspirate analysis. Certain clinical features may suggest PsA in the absence of psoriasis (psoriatic arthritis sine psoriasis), such as distal joint involvement, an asymmetric distribution, nail lesions, dactylitis, and the family history $[10,11]$.

Laboratory findings in psoriasis and PsA are nonspecific and not differentiate it from other forms of inflammatory arthritis. Autoantibodies such as rheumatoid factor, anti-nuclear antibodies (ANA), and anti-citrullinated peptide antibodies (ACPA) are present in a minority of patients. RF is found in 2 to $10 \%$ of psoriatic arthritis patients [12].

The aim of this study is to assess the frequency and levels of rheumatoid factor in psoriasis patients, and describe its relationship with the different disease patterns of psoriasis including the demographic, clinical patient characteristics and comorbidities.

\section{Methods}

\section{Study design}

This case control study was carried out between April 2018 and March 2020 on total number of 90 subjects divided into 2 groups: group (I): 50 patients with psoriasis vulgaris as patient group and group (II): 40 ageand sex-matched healthy volunteers as a control group and was conducted with approval of ethical committee in faculty of medicine Menoufia University. The diagnosis of psoriasis was based on clinical findings and assessment by dermatologist.

Patients with history of malignancies, other dermatological diseases than psoriasis vulgaris, symptoms of any infection were excluded from the study.

A formal consent that was in accordance with the Helsinki Declaration in 1975 (revised in 2000) was obtained from all participants before starting the study.

Assessments were carried out by face-to-face clinical interviews and patients were excluded if they had a history of rheumatoid arthritis, or other autoimmune disease and pregnancy. Serum rheumatoid factor was measured to patients and controls was measured by nephlometric method.

Complete general examination, thorough dermatological examination with determination for the site of the lesion, the course of psoriasis was evaluated as progressive or stationary during history taking and the onset of psoriasis was classified as early onset which arises at or before the age of 40 and late-onset psoriasis which occurs afterwards the age of 40.

Sample size calculated with right size software assuming the prevalence of psoriasis. Data were collected on a specifically designed questionnaire to record sociodemographic and clinical details such as comorbid diagnoses, age at onset of illness, duration of illness, and family history.

Psoriasis Area and Severity Index (PASI) score was used for assessing psoriasis severity. The body of patients was divided into four parts: (1) head (h) $(10 \%$ of a person's skin); (2) upper extremity (u) (20\%); (3) the trunk (t) (30\%); (4) lower extremity (l) (40\%). The area of skin percentage affected was calculated and grading was done as follows: $0,0 \%$ affected area; 1 , $<10 \%$ affected area; $2,10-29 \%$ affected area; 3, 30-49\% affected area; 4, 50-69\% affected area; 5, 70-89\% affected area; 6, 90-100\% affected area. Three clinical parameters within each part of the skin (A) were assessed to detect the severity: erythema (E), desquamation (D), and induration (I). These clinical signs were estimated as follows: 0 , no signs; 1 , mild; 2 , moderate; 3 , severe; 4 , very severe clinical signs. Then, the sum of the severity scores for the clinical signs was calculated for each area of skin and then multiplied by the score for that affected part and by the weight of this part ( 0.1 for the head; 0.2 for upper extremities; 0.3 for the trunk; 0.4 for lower extremities) [13]. Lastly, the PASI score was calculated as follows: PASI score $=0.1(\mathrm{Eh}+\mathrm{Ih}+\mathrm{Dh})$ $\mathrm{Ah}+0.2(\mathrm{Eu}+\mathrm{Iu}+\mathrm{Du}) \mathrm{Au}+0.3(\mathrm{Et}+\mathrm{It}+\mathrm{Dt}) \mathrm{At}+0.4$ $(\mathrm{El}+\mathrm{Il}+\mathrm{Dl}) \mathrm{Al}$. PASI score ranged from 0 to 72 : less than 7, mild disease; 7-12, moderate psoriasis; more than 12 , severe psoriasis [14]. 


\section{Statistical analysis}

The data collected were tabulated and analyzed by SPSS (statistical package for the social science software) statistical package version 20.0 (IBM Corp., USA). Continuous variables are presented as mean \pm standard deviation (SD). Student's $t$ test was used for normally distributed data and Mann-Whitney $U$ test for the not normally distributed data comparison between the 2 groups. For the qualitative data, it was expressed in the form of number and percentage (No and \%) then it was analysed by applying $X^{2}$ (chi-square) and Fisher's exact for comparison between two or more independent qualitative variables normally distributed. The level of significance was set at $P<.05$.

\section{Results}

The baseline sociodemographic profile characteristics of the patients who had psoriasis (case subjects) and those who remained free of psoriasis (controls) are shown in Table 1. There was no significant difference between patients and control as regards age, gender, and presence of comorbidities. Age was $43.1 \pm 14.7$ in psoriasis patients vs. $38.7 \pm 9.1$ in control group. Among psoriatic patients 19 (38\%) were females vs 19 (47.5\%) in control group, while males were $31(62 \%)$ in psoriasis patients vs. 21 (52.55) in control group. Concerning associated comorbidities, $6 \%$ psoriasis patients have diabetes mellitus (DM), 4\% have cardiovascular disease (CVD), and $4 \%$ have both DM and CVD. There was significant statistical difference between both groups as regard positive family history of psoriasis. Thirty-two percent of patients with psoriasis have positive family history of psoriasis vs. $7.5 \%$ in control group (Table 1).

Comparison of clinical features of psoriasis patients revealed that $54 \%$ have early onset disease vs. $46 \%$ have late onset disease. Sixty-eight percent have progressive course while $32 \%$ have stationary course. Fifty-eight percent have scalp affection, 30\% have nail affection, $56 \%$ have palm affection, $45 \%$ have kobenerization, and $6 \%$ have dactylitis. Illness severity assessed by PASI showed that $40 \%$ have mild disease vs. $38 \%$ have moderate disease, and $22 \%$ have severe disease. Pattern of psoriatic skin involvement was $26 \%$ have axial affection, $32 \%$ have extremities affection and $52 \%$ have axial and extremities affection. Disease duration in psoriasis patients was $4.5 \pm 3.5$ years. PASI was $16.3 \pm 13.4$ (Table 2).

Twenty-percent of psoriasis patients have psoriatic arthritis. Thirty-percent was axial and $70 \%$ was peripheral arthritis. Eighteen percent of psoriasis patients had only arthralgia without true arthritis (Table 3).

There was significant statistical difference between psoriasis patients and control as regards rheumatoid factor positivity and titer. Rheumatoid factor was positive in $30 \%$ of psoriatic patients while only $10 \%$ of control had positive result. Rheumatoid factor level was $63.8 \pm 186.7 \mathrm{IU} /$ $\mathrm{ml}$ in psoriasis vs. $9.3 \pm 12.3 \mathrm{IU} / \mathrm{ml}$ in control (Table 4).

There was no significant statistical difference between psoriasis patients with or without arthritis as regard rheumatoid factor positivity and titer. Rheumatoid factor was positive in $20 \%$ in psoriatic patients with arthritis vs. $26 \%$ in psoriatic patients without arthritis. RF was $43.2 \pm 103.2 \mathrm{IU} / \mathrm{ml}$ in psoriatic patients with arthritis vs. $40.2 \pm 53.5 \mathrm{IU} / \mathrm{ml}$ in psoriatic patients without arthritis (Table 5).

There was no significant statistical difference in rheumatoid factor in psoriasis patients as regard disease severity, onset, course, site of affection, presence of scalp, nail affection, and presence of dactylitis (Table 6).

\section{Discussion}

Psoriasis encompasses several distinct clinical phenotypes representing a morphological, anatomical, and qualitative spectrum of the same disease. Disease

Table 1 Demography and comorbidities of the studied patients

\begin{tabular}{|c|c|c|c|c|c|c|}
\hline & $\begin{array}{l}\text { Patients } \\
N=50\end{array}$ & & $\begin{array}{l}\text { Control } \\
N=40\end{array}$ & & Test of significance & $P$ value \\
\hline & Mean \pm SD & & Mean \pm SD & & & \\
\hline Age & $43.1 \pm 14.7$ & & $38.7 \pm 9.1$ & & 1.6 & 0.1 \\
\hline Sex & $N$ & $\%$ & $N$ & $\%$ & & \\
\hline $\mathrm{F}$ & 19 & 38 & 19 & 47.5 & 0.8 & 0.3 \\
\hline M & 31 & 62 & 21 & 52.5 & & \\
\hline $\mathrm{DM}$ & 3 & 6 & 0 & 0 & 0.8 & 0.2 \\
\hline CVD & 2 & 4 & 0 & 0 & 0.5 & 0.5 \\
\hline DM and CVD & 2 & 4 & 0 & 0 & 0.5 & 0.5 \\
\hline Family history & 16 & 32 & 3 & 7.5 & 4.7 & 0.004 \\
\hline
\end{tabular}

D.M diabetes mellitus, CVD cerebrovascular disease 
Table 2 Clinical characteristic of psoriasis in the studied patients

\begin{tabular}{lll}
\hline & N & $\%$ \\
\hline Onset & & \\
$\cdot$ Early & 27 & $54 \%$ \\
$\cdot$ Late & 23 & $45 \%$ \\
Course & & \\
$\cdot$ Progressive & 34 & $68 \%$ \\
- Stationary & 16 & $32 \%$ \\
Scalp affection & 29 & $58 \%$ \\
Nail affection & 15 & $30 \%$ \\
Palm affection & 28 & $56 \%$ \\
Kobenerization & 23 & $45 \%$ \\
Dactylitis & 3 & $6 \%$ \\
Severity & & \\
• Mild & 20 & $40 \%$ \\
$\cdot$ Moderate & 19 & $38 \%$ \\
- Severe & 11 & $22 \%$ \\
Site of skin affection & & \\
$\quad$ Axial & 8 & $32 \%$ \\
Extremities & $16 \%$ \\
Axial and extremities & 26 & $52 \%$ \\
Duration of disease in years & Mean \pm SD & \\
PASl score & $4.5 \pm 3.5$ & \\
\hline
\end{tabular}

Table 3 Psoriatic arthritis characters in psoriatic patients

\begin{tabular}{lll}
\hline & N & $\%$ \\
\hline $\begin{array}{lll}\text { Psoriatic arthritis } \\
\quad \text { Present }\end{array}$ & & \\
Type & 10 & \\
Axial & & $30 \%$ \\
Peripheral & 3 & $70 \%$ \\
Arthralgia & 7 & $18 \%$ \\
\hline
\end{tabular}

classification has been dependent on clinical features mainly the distribution and morphology. The updated classification of psoriasis include four main pattern: plaque-type, guttate, generalized pustular psoriasis, and erythrodermic psoriasis, and further sub phenotypes according to distribution (limited vs. widespread), anatomical localization (flexural, scalp, palms/soles/nail), size (small vs. large) and thickness (thick vs. thin) of plaques, onset (early vs. late), and disease activity (active vs. inactive) $[15,16]$.

Arthritis appears after skin lesions in most patients with PsA. Conversely, the arthritis precedes the skin lesions in 13 to $17 \%$ of patients [17].

There are no clear guidelines regarding the indications for ordering RF in psoriasis. When RF is combined with other clinical data (such as C-reactive protein and joint count), prediction could be improved. Rheumatoid factors have been found in up to $4 \%$ of healthy individuals. The reported incidence may be higher in older subjects without rheumatic disease, ranging from 3 to $25 \%$. However, other studies have reported that the prevalence of $\mathrm{RF}$ among healthy older individuals is low and does not increase with aging [18].

The present study assessed the frequency and level of rheumatoid factor in psoriasis patients and healthy controls. There was significant statistical difference between psoriasis patients and control as regard rheumatoid factor positivity. Rheumatoid factor was positive in $30 \%$ of psoriatic patients while only $10 \%$ of control had positive result. Rheumatoid factor level was $63.8 \pm 186.7 \mathrm{IU} / \mathrm{ml}$ in psoriasis vs. $9.3 \pm 12.3 \mathrm{IU} /$ $\mathrm{ml}$ in control. Thirty percent of psoriasis patients have positive rheumatoid factor vs. $10 \%$ of control. These findings are not in line with the seronegativity concept of psoriasis [19]. This might be explained by racial factors or associated occult rheumatoid arthritis in psoriasis patients.

This study revealed no significant statistical difference between psoriasis patients with or without arthritis as regard rheumatoid factor positivity. Rheumatoid factor was positive in $20 \%$ in psoriatic patients with arthritis vs. $26 \%$ in psoriatic patients without arthritis. It was $43.2 \pm$ $103.2 \mathrm{IU} / \mathrm{ml}$ in psoriatic patients with arthritis vs. $40.2 \pm$ $53.5 \mathrm{IU} / \mathrm{ml}$ in psoriatic patients without arthritis. $20 \%$ of psoriasis patients have psoriatic arthritis. Thirty percent was axial and $70 \%$ was peripheral arthritis. Eighteen percent of total psoriasis patients have only arthralgia without true arthritis.

Table 4 Rheumatoid factor in the studied groups

\begin{tabular}{|c|c|c|c|c|c|c|}
\hline & $\begin{array}{l}\text { Patients } \\
N=50\end{array}$ & & $\begin{array}{l}\text { Control } \\
N=40\end{array}$ & & Test of significance & $P$ value \\
\hline Rheumatoid factor & $63.8 \pm 186.7$ & & $9.3 \pm 12.3$ & & 2.6 & 0.01 \\
\hline Rheumatoid factor & $N$ & $\%$ & $N$ & $\%$ & & \\
\hline Positive & 15 & $30 \%$ & 4 & $10 \%$ & 5.5 & 0.01 \\
\hline Negative & 35 & $70 \%$ & 36 & $90 \%$ & & \\
\hline
\end{tabular}


Table 5 Rheumatoid factor in psoriatic patients with and without arthritis

\begin{tabular}{|c|c|c|c|c|c|c|}
\hline \multirow[b]{2}{*}{ Rheumatoid factor } & \multicolumn{2}{|c|}{$\begin{array}{l}\text { Psoriatic patients with arthritis } \\
n=10\end{array}$} & \multicolumn{2}{|c|}{$\begin{array}{l}\text { Psoriatic patients without arthritis } \\
n=40\end{array}$} & \multirow[t]{2}{*}{ Test of sig } & \multirow[t]{2}{*}{$P$ value } \\
\hline & $\mathrm{N}$ & $\%$ & N & $\%$ & & \\
\hline - Positive & 2 & $4 \%$ & 13 & $26 \%$ & 0.5 & 0.7 \\
\hline - Negative & 8 & $16 \%$ & 27 & $54 \%$ & & \\
\hline \multirow[t]{2}{*}{ Rheumatoid factor titre } & \multicolumn{2}{|l|}{ Mean \pm SD } & \multicolumn{2}{|l|}{ Mean \pm SD } & & \\
\hline & \multicolumn{2}{|l|}{$43.2 \pm 103.2$} & $40.2 \pm 53.5$ & & 0.5 & 0.5 \\
\hline
\end{tabular}

There is a significant risk of psoriatic arthritis (7-48\%) in patients with plaque-type psoriasis. Hence, it is recommended to evaluate for its presence by history and clinical examination, and if necessary, by appropriate imaging. PsA is a seronegative arthritis; RF and CCP are negative in most patients with PsA, and if patients do have positive test for RF or CCP, the titers are usually low [19]. In a study comparing patients with RA or PsA and controls, the mean RF and anti-CCP titer values were higher in patients with RA compared with PsA. Titers in patients with PsA were similar to values in controls [20].

Average severity of psoriasis was moderate in the participants in this study. Illness severity assessment showed that $40 \%$ have mild disease instead 38\% have moderate disease and $22 \%$ have severe disease. There is no associated relationship between rheumatoid factor status and severity of psoriasis in both sexes. Psoriasis severity was rated on BSA scale which is dependent on body surface area. the psoriasis area severity index appears to be the most reliable severity score in the assessment of psoriasis [21]. Many potential factors contribute to severity of psoriasis. Genetic factors include HLA-Cw6 and mutations of CARD14. Environmental risk factors have been implicated also, including infections, medications, hypovitaminosis $\mathrm{D}$, and lifestyle [22, 23].

There was a significant statistical difference between both groups as regard positive family history of psoriasis. Thirty-two percent of patients with psoriasis have positive family history of psoriasis vs. 7.5\% in control group.

There are multiple clinical subtypes of psoriasis. Chronic plaque psoriasis, the most common presentation of psoriasis, most commonly presents with sharply defined erythematous plaques with overlying silvery scale. The scalp, extensor elbows and knees are common locations for plaque psoriasis. A diagnosis of psoriasis can be made by history and physical examination in most cases. Occasionally, a skin biopsy is needed to rule out other disorders. Nail affection in psoriasis include nail pits and onycholysis occur in about 80 $\%$ of patients with Psoriatic arthritis. The severity of

Table 6 Relationship of rheumatoid factor status to severity and pattern of psoriasis

\begin{tabular}{|c|c|c|c|c|c|c|c|}
\hline \multirow[b]{2}{*}{ Severity } & \multicolumn{2}{|c|}{ Positive } & \multicolumn{3}{|c|}{ Negative } & \multirow[t]{2}{*}{ Test } & \multirow[t]{2}{*}{$P$ value } \\
\hline & N & $\%$ & N & & $\%$ & & \\
\hline Mild & 5 & 25 & 15 & & 75 & 1.6 & 0.6 \\
\hline Moderate & 5 & 26.3 & 14 & & 73.7 & & \\
\hline Severe & 5 & 45.4 & 6 & & 54.6 & & \\
\hline Onset & $N$ & $\%$ & $N$ & & $\%$ & & \\
\hline Early & 7 & 25.9 & 20 & & 74.1 & 0.4 & 0.5 \\
\hline Late & 8 & 34.8 & 15 & & 65.2 & & \\
\hline Course & $N$ & $\%$ & $N$ & & $\%$ & & \\
\hline Progressive & 8 & 23.5 & 26 & & 76.5 & 2.1 & 0.1 \\
\hline Stationary & 7 & 43.8 & 9 & & 56.2 & & \\
\hline Site of affection & $N$ & $\%$ & $N$ & & $\%$ & & \\
\hline Axial & 5 & 62.5 & 3 & & 37.5 & 5.4 & 0.06 \\
\hline Peripheral & 5 & 31.3 & 11 & & 68.8 & & \\
\hline Both & 5 & 19.2 & 21 & & 80.8 & & \\
\hline Scalp affection & 6 & 20.7 & 23 & & 79.3 & 2.8 & 0.09 \\
\hline Nail affection & 3 & 20 & 12 & & 80 & 2.3 & 0.5 \\
\hline Palm affection & 7 & 25 & 21 & & 75 & 3.9 & 0.2 \\
\hline Dactylitis & 1 & 33.3 & 2 & 66.7 & & 0.01 & 0.6 \\
\hline Kobnerization & 8 & 34.7 & 15 & & 65.3 & 0.4 & 05 \\
\hline
\end{tabular}


psoriatic nail involvement correlates well with severity of both skin and joint affection [24, 25].

Plaque psoriasis is the most common pattern of psoriasis in this study, accounting for more than $90 \%$ of all cases. In this study, analysis of clinical characteristics of psoriasis patients reveals that $54 \%$ have early onset disease vs. $46 \%$ have late onset disease. Sixty-eight percent have progressive course while $32 \%$ have stationary course. Fifty-eight percent have scalp affection, $30 \%$ have nail affection, 56\% have palm affection, $45 \%$ have kobenerization, and $6 \%$ have dactylitis. Among our patients with psoriasis, $26 \%$ have axial affection, $32 \%$ have extremities affection, and $52 \%$ have axial and extremities affection.

The inclusion of patients with variable patterns of psoriasis is an important advantage of this study; clinical diagnosis is established on clinical diagnosis of psoriasis. RF is a simple test used, and a major advantage of RF lies in its easy availability in most medical laboratories. Further, the study participants were systematically recruited. Based on these data, our sample seems to be representative for Menoufia population of patients diagnosed with psoriasis in tertiary hospital care.

Role of biomarkers is not only limited up to etiopathogenesis of psoriasis but also correlate with severity of the current psoriasis flares. The recent knowledge of the role of the immune system in psoriasis has had a significant impact on therapeutics that target specific immunologic aspects of psoriasis $[26$, 27]. It is recommended that more epidemiologic studies should be conducted in Egypt for estimating the accurate prevalence of psoriasis patterns.

\section{Limitations of the study}

Study global sample size may be an important limitation of the study, and also the interviewers were not blinded. Isotypes of $\operatorname{Rf}(\operatorname{IgA}$ and $\operatorname{IgG})$, anti-ccp, and HLA B 27 were not evaluated. The absence of other medical disorders in subjects was based on history given by the subjects and not by any clinical workup of participants. Finally, we investigated a sample of patients to rheumatology and dermatology tertiary hospital care, and consequently, our findings cannot be generalized to patients with milder psoriasis treated in primary care.

\section{Conclusions}

This study included psoriasis which is a major health issue in general population and explored the role of immune dysregulation along. Psoriasis was associated with higher seropositivity of RF compared to age-matched non-psoriatic healthy controls. Raised RF was not associated with severity or pattern of psoriasis. In conclusion, our study suggests that immune dysregulation has an important role in the.

\section{Abbreviations}

ACPA: Anti-citrullinated peptide antibodies; ANA: Anti-nuclear antibodies; CCP: Cyclic citrullinated peptide; DIP: Distal interphalangeal joints; IgG: Immunoglobulin G; PsA: Psoriatic arthritis; PASI: Psoriasis Area and Severity Index; RA: Rheumatoid arthritis; RF: Rheumatoid factor.

\section{Acknowledgements}

Authors appreciate the contribution from resident of dermatology \& rheumatology and internal medicine departments.

\section{Authors' contributions}

AY gave the idea of the review and design of the study. EE contributed by writing main text and conclusion of the manuscript. EZ contributed in tables and figure results analysis. WS shared in data collection all parts of the manuscript, and $A B$ share with laboratory assessment. All authors read and approved the final manuscript.

\section{Funding \\ No funding.}

\section{Availability of data and materials}

The authors confirm that the data supporting the findings of this study are available within the article.

\section{Declarations}

Ethics approval and consent to participate

The study was submitted to and approved by Menoufia Faculty of Medicine Ethics Committee and a statement to this effect in the "Methods" section of the manuscript. Number of ethical approval: 882021. Date of approval 8 August 2021. The consent from study participants was verbal which is considered enough in descriptive studies.

\section{Consent for publication}

It was done.

Competing interests

All authors declare that they have no competing interests.

\section{Author details}

${ }^{1}$ Rheumatology Immunology Division, Internal Medicine Department Faculty of Medicine Menoufia University, Shebin El Kom, Menoufia, Egypt. ${ }^{2}$ Rheumatology, Egyptian School of Immunology, Cairo, Egypt. ${ }^{3}$ Dermatology, Andrology and STDs Department, Faculty of Medicine, Menoufia University, Shebin El Kom, Menoufia, Egypt. ${ }^{4}$ Clinical Pathology Department, NLI, Menoufia University, Shebin El Kom, Menoufia, Egypt.

Received: 30 April 2021 Accepted: 6 November 2021

Published online: 24 November 2021

\section{References}

1. Sutton B, Corper A, Bonagura V, Taussig M (2000) The structure and origin of rheumatoid factors. Immunol Today 21:177

2. Steiner G, Smolen J (2002) Autoantibodies in rheumatoid arthritis and their clinical significance. Arthritis Res 4(Suppl 2):S1-S5. https://doi.org/ 10.1186/ar551 Epub 2002 Apr 26. PMID: $12110150 ;$ PMCID: PMC3238219

3. Ingegnoli F, Castelli R, Gualtierotti R (2013) Rheumatoid factors: clinical applications. Dis Markers. 35(6):727-734. https://doi.org/10.1155/2013/ 726598 
4. Tan EM, Smolen JS (2016) Historical observations contributing insights on etiopathogenesis of rheumatoid arthritis and role of rheumatoid factor. J Exp Med 213:1937

5. Shmerling RH, Delbanco TL (1992) How useful is the rheumatoid factor? An analysis of sensitivity, specificity, and predictive value. Arch Intern Med 152:2417

6. Nestle FO, Kaplan DH, Barker J (2009) Psoriasis. N Engl J Med 361:496

7. Merola JF, Li T, Li WQ et al (2016) Prevalence of psoriasis phenotypes among men and women in the USA. Clin Exp Dermatol 41:486-489

8. Ruiz de Morales JMG, Puig L, Daudén E, Cañete JD, Pablos JL, Martín AO, Juanatey CG, Adán A, Montalbán X, Borruel N, Ortí G, Holgado-Martín E, García-Vidal C, Vizcaya-Morales C, Martín-Vázquez V, González-Gay MÁ (2020) Critical role of interleukin (IL)-17 in inflammatory and immune disorders: an updated review of the evidence focusing in controversies. Autoimmunity Reviews 19(1):102429

9. Turkiewicz AM, Moreland LW (2007) Psoriatic arthritis: current concepts on pathogenesis-oriented therapeutic options. Arthritis Rheum 56:1051

10. Veale DJ, Fearon U (2015) What makes psoriatic and rheumatoid arthritis so different? RMD Open 1:e000025

11. Merola JF, Espinoza LR, Fleischmann R (2018) Distinguishing rheumatoid arthritis from psoriatic arthritis. RMD Open 4(2):e000656. Published 2018 Aug 13. https://doi.org/10.1136/rmdopen-2018-000656

12. Punzi L, Podswiadek M, Oliviero F, Lonigro A, Modesti V, Ramonda R, Todesco S (2007) Laboratory findings in psoriatic arthritis. Reumatismo. 59(Suppl 1):52-55

13. Farag AG, Elshayb EE, Al Sharaky DR, Elshafey EN, Abo Khadra AA (2019) Role of HCV Infection in Psoriasis: A Clinical and Immunohistochemical Study. Journal of Clinical and Diagnostic Research. 13(5):WC01-WC06

14. Hemida AS, Hammam MA, Salman ATA, Shehata WA (2020) Smad7 in psoriasis vulgaris patients: A clinical and immunohistochemical study. J Cosmet Dermatol. 00:1-8

15. Di Meglio P, Villanova F, Nestle FO (2014) Psoriasis. Cold Spring Harb Perspect Med 4(8):a015354. Published 2014 Aug 1. https://doi.org/10.1101/ cshperspect.a015354

16. Griffiths CE, Christophers E, Barker JN, Chalmers RJ, Chimenti S, Krueger GG, Leonardi C, Menter A, Ortonne JP, Fry L (2007) A classification of psoriasis vulgaris according to phenotype. Br J Dermatol. 156(2):258-262. https://doi.org/10.1111/j.1365-2133.2006.07675.x PMID: 17223864
17. Sankowski AJ, Lebkowska UM, Cwikła J, Walecka I, Walecki J (2013) Psoriatic arthritis. Pol J Radiol. 78(1):7-17. https://doi.org/10.12659/PJR.883763

18. Tiwari V, Jandu JS, Bergman MJ (2020) Rheumatoid Factor. [Updated 2020 Jul 27]. In: StatPearls. StatPearls Publishing, Treasure Island Available from: https://www.ncbi.nlm.nih.gov/books/NBK532898/

19. Mak RK, Hundhausen C, Nestle FO (2009) Progress in understanding the immunopathogenesis of psoriasis. Actas Dermosifiliogr. 100(Suppl 2):2-13. https://doi.org/10.1016/s0001-7310(09)73372-1

20. Mease PJ, Armstrong AW (2014) Managing patients with psoriatic disease: the diagnosis and pharmacologic treatment of psoriatic arthritis in patients with psoriasis. Drugs. 74(4):423-441. https://doi.org/10.1007/ s40265-014-0191-y

21. Naldi $L$ (2010) Scoring and monitoring the severity of psoriasis. What is the preferred method? What is the ideal method? Is PASI passé? facts and controversies. Clin Dermatol. 28(1):67-72. https://doi.org/10.1016/j.clind ermatol.2009.03.001 PMID: 20082954

22. Lee EB, Wu KK, Lee MP, Bhutani T, Wu JJ (2018) Psoriasis risk factors and triggers. Cutis. 102(5S):18-20 PMID: 30566552

23. El-Farargy SM, Ghanayem NM, Elrashidy AM (2020) Correlation between vitamin D serum level and severity of psoriasis. 33:3.1016-3.1020. https:// www.mmj.eg.net/article.asp?issn=1110-2098; year $=2020$; volume $=33$; issue $=3 ;$ spage $=1016$; epage $=1020 ;$ aulast $=$ El-Farargy;type $=0$

24. Gisondi P, Bellinato F, Girolomoni G (2020) Topographic Differential Diagnosis of Chronic Plaque Psoriasis: Challenges and Tricks. J Clin Med 9(11):3594. Published 2020 Nov 8. https://doi.org/10.3390/jcm9113594

25. Naldi L, Gambini D (2007) The clinical spectrum of psoriasis. Clin Dermatol. 25(6):510-518. https://doi.org/10.1016/j.clindermatol.2007.08.003 PMID: 18021886

26. Hawkes JE, Chan TC, Krueger JG (2017) Psoriasis pathogenesis and the development of novel targeted immune therapies. J Allergy Clin Immunol. 140(3):645-653. https://doi.org/10.1016/j.jaci.2017.07.004

27. Verheul MK, Fearon U, Trouw LA et al (2015) Biomarkers for rheumatoid and psoriatic arthritis. Clinical Immunology 161:2-10

\section{Publisher's Note}

Springer Nature remains neutral with regard to jurisdictional claims in published maps and institutional affiliations.

\section{Submit your manuscript to a SpringerOpen ${ }^{\circ}$ journal and benefit from:}

- Convenient online submission

- Rigorous peer review

- Open access: articles freely available online

- High visibility within the field

- Retaining the copyright to your article

Submit your next manuscript at springeropen.com 